\title{
Study on Home Chairs Design Evaluation for Low-and Middle-income Groups Based on User Experience
}

\author{
Xianshu Leng ${ }^{1,2,3}$, *Hong Zhang ${ }^{1,2,3}$, Ding Feng ${ }^{1,2,3}$ \\ ${ }^{1}$ School of Mechanical Engineering, Yangtze University, Jingzhou, Hubei, 434023, China; \\ ${ }^{2}$ Hubei Engineering Research Center of Oil and Gas Drilling and Completion Tools, Yangtze University, \\ Jingzhou, Hubei, 434023 \\ ${ }^{3}$ Hubei Cooperative Innovation Center of Unconventional Oil and Gas, Yangtze University, Wuhan, Hubei, \\ 430100
}

\begin{abstract}
Pay attention to the home living environment of low-and middle-income groups, study the user-centered design evaluation method to guide the design of home chairs suitable for low-and middle-income groups. Introducing Analytic Hierarchy Process (AHP) into home chairs' design evaluation, it establishes a different layer and different elements structure model based on sensory experience, behavioral experience, emotional experience and economic experience from the point of user experience. Scoring each element, it calculates and determines the weight value of every element, and forms an evaluation method of home chairs for low-and middle-income Groups. Using the method to evaluate the design schemes of 3 home chairs, it obtains the optimal scheme. Then, surveying the market sales data to verify the accuracy of the result. The evaluation method consists of four major elements: sensory experience $\left(\mathrm{B}_{1}\right), 27 \%$; behavior experience $\left(\mathrm{B}_{2}\right), 41 \%$; emotional experience $\left(\mathrm{B}_{3}\right), 10 \%$; economic experience $\left(\mathrm{B}_{4}\right), 22 \%$. The method can effectively solve the complex comparison of multiple elements in design evaluation and provide a comprehensive method combining qualitative and quantitative methods for product design, and provides reference for products design and evaluation of the same type.
\end{abstract}

Key words: low-and middle-income groups, user experience, home chairs, analytic hierarchy process(AHP), design evaluation

\section{Introduction}

With the population of urban increasing year by year, housing supply exceeds demand, which directly leads to the outrageous housing prices for low-and middle-income groups. For low-and middle-income groups, they have to reduce the housing area. It necessary for users to improve the economic practicability and space saving of furniture in narrow rooms. For them, the increase in comfort does not mean that the user experience of home chairs increases. Conversely, economic and spatial considerations are not well thought out, leading to a decline in the user experience of home chairs and even some consumers will give up on this choice directly during the purchase process. In the era of experience economy, the market competition is intensified and the user demand is diversified. Therefore, how to balance the relationship of various elements in home chairs design, improving the user experience of home chairs for low-and middle-income groups, creating a comfortable and warm home environment has become an important research content in today's design. 


\section{Positioning of low-and middle-income groups}

In 2018, the Chinese Academy of Social Sciences issued the "Strategic Choice of the Distribution of Middle-income Groups and the Expansion of Middle-income Groups", showing that China's low-income groups account for 35\% of China's total population and low- and middle-income groups account for $22.7 \%$. In this paper, we refer to these $35 \%$ and $22.7 \%$ people as low- and middle-income groups. These groups have no economic strength to buy villas or big dwelling-size, can only buy small dwelling-size or rent. Their annual family income is between 30,000 120,000 yuan, of which 30,000 80,000 yuan is the majority. They live in cramped spaces, prefer economical and cost-effective products. Therefore, it is necessary to fully consider economy, practicality, occupying less space and other elements in the design.

\section{Theory and method}

\subsection{The theory of User Experience}

Meeting the needs of users is the key to product design. User experience is to make the product meet the needs of users and reflect the will of users from the perspective of users ${ }^{[1]}$. The biggest difference between user experience design and traditional design is that traditional design is mainly concerned with the form and function of the product itself when designing ${ }^{[2]}$. Simple form and function design is not a real product design. It is just a behavioral design, which is the dynamic behavior of the user's preset product by the designer ${ }^{[3]}$. In other words, the presupposition is just a hypothesis, the idea and intention in the designer's mind, and finally imposed on the user to accept ${ }^{[4]}$. However, user experience design emphasizes "people-oriented". Its realization reflects designers' material care and emotional care for users, which is the key to product development and design in the right direction.

\subsection{Analytic hierarchy process (AHP)}

In 1970, AHP proposed by Saaty, an American operations research scientist, can transform complex and abstract problems into the ranking of weights, scores or importance of the lowest-level sub-problems, thus effectively solve multi-element comparison ${ }^{[5]}$. Its general steps are as follows: first, the problem is hierarchical, usually divided into three layers, namely the target layer, the criteria layer, and the sub-criteria layer. Secondly, the target is decomposed into different layers and different elements according to the nature of the target, and a multi-layer analytical structure model (AHM) is constructed according to the interrelated influences and subordination among the elements. Finally, the comprehensive weight value or relative merit order of the lowest layer (for decision-making schemes, measures, etc.) relative to the highest layer (total target) is calculated and determined ${ }^{[6-7]}$.

\section{Design evaluation system}

In this paper, AHP is used as the subjective evaluation method to propose the AHM of home chairs design for low-and middle-income groups.

\subsection{The establishment of AHM}

1) Target layer A. There is only one element in the target layer, which is the best design of home chairs for low-and middle-income groups.

2) Criteria layer B. In "Experience Marketing", Bernd H. Schmitt divides the experience into five parts: sensory experience, emotional experience, thinking experience, behavioral experience and related experience ${ }^{[8]}$. Based on the analysis of user psychology and the definition of user experience in furniture design, the home chairs will be analyzed from four aspects, namely the sensory experience $\left(\mathrm{B}_{1}\right)$, behavioral experience $\left(B_{2}\right)$, emotional experience $\left(B_{3}\right)$ and economic experience $\left(B_{4}\right)$, to form the criterion layer in the evaluation system. 
3) Sub-criteria layer C. The criteria layer is further refined into sub-criteria layers. For sensory experience, the sub-criteria layer can be further subdivided into four elements: shape $\left(\mathrm{C}_{1}\right)$, color $\left(\mathrm{C}_{2}\right)$, decoration $\left(\mathrm{C}_{3}\right)$, and material $\left(\mathrm{C}_{4}\right)$. For behavioral experience, the sub-criteria layer can be subdivided into three elements: function $\left(\mathrm{C}_{5}\right)$, structure $\left(\mathrm{C}_{6}\right)$ and ergonomics $\left(\mathrm{C}_{7}\right)$. In addition, combined with the inherent characteristics of low-and middle-income groups' small housing area, the sub-criteria layer adds the element of mobile storage $\left(\mathrm{C}_{8}\right)$. With the improvement of material living standards, personalized products that reflect respecting are deeply loved by users, and good detail design reflects the high quality and high grade of the product, which gives the user a sense of belonging ${ }^{[9]}$. Then, for emotional experience, the sub-criteria layer can be subdivided into three elements: personalization $\left(\mathrm{C}_{9}\right)$, detail $\left(\mathrm{C}_{10}\right)$ and sense of belonging $\left(\mathrm{C}_{11}\right)$. For economic experience, it can be three elements: price $\left(C_{12}\right)$, environmental protection $\left(C_{13}\right)$ and use cycle $\left(C_{14}\right)$ [10].

The AHM of home chairs design for the low- and middle-income groups is shown in Figure1.

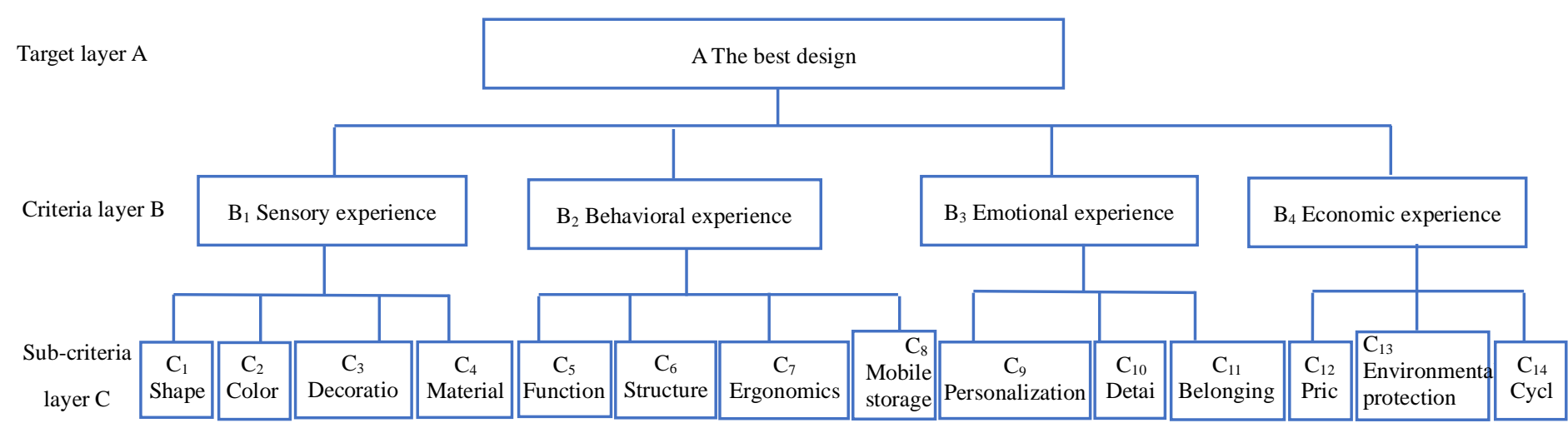

Figure 1. The AHM of home chairs design for low-and middle-income groups

4.2 Judgment matrix construction and weight calculation

In order to determine the weight of elements at each layer, based on the corresponding elements at the upper layer, the next layer of every element is compared with each other ${ }^{[11]}$. If a relationship is established between the upper layer $\mathrm{A}$ and the next layer $\mathrm{B}$, the judgment matrix can be established ${ }^{[6]}$, as shown in Table 1 .

Table 1. Judgment matrix construction

\begin{tabular}{|c|c|c|c|c|}
\hline $\mathbf{A}$ & $\mathbf{B}_{\mathbf{1}}$ & $\mathbf{B}_{\mathbf{2}}$ & $\cdots$ & $\mathbf{B}_{\mathbf{n}}$ \\
\hline $\mathbf{B}_{\mathbf{1}}$ & $\mathrm{b}_{11}$ & $\mathrm{~b}_{12}$ & $\cdots$ & $\mathrm{b}_{1 \mathrm{n}}$ \\
\hline $\mathbf{B}_{\mathbf{2}}$ & $\mathrm{b}_{21}$ & $\mathrm{~b}_{22}$ & $\cdots$ & $\mathrm{b}_{2 \mathrm{n}}$ \\
\hline$\vdots$ & $\vdots$ & $\vdots$ & & $\vdots$ \\
\hline $\mathbf{B}_{\mathbf{n}}$ & $\mathrm{b}_{\mathrm{n} 1}$ & $\mathrm{~b}_{\mathrm{n} 2}$ & $\cdots$ & $\mathrm{b}_{\mathrm{nn}}$ \\
\hline
\end{tabular}

Where $b_{i j}=b_{i}: b_{j}$, represent the importance of the element $b_{i}$ and the element $b_{j}$ for the upper element $A$, where $b_{i j}=1 / b_{j i}, b_{i j}>0$, the value of 
$b_{i j}$ is $1 \sim 9$ and its reciprocal according to its relative importance ${ }^{[12]}$. Then, the judgment matrix is constructed.

15 decision makers, composed of 2 furniture designers, 3 furniture factory workers, 8 users with annual income of 30,000-80,000 yuan, and 2 furniture design graduate students, evaluated the elements of each layer according to the above rules and constructed a judgment matrix.

1) Construct the target layer judgment matrix A and determine the weight, as shown in Table 2.

Table 2. The judgment matrix and weight of target layer $A$

\begin{tabular}{|c|c|c|c|c|c|}
\hline$A$ & $B_{1}$ & $B_{2}$ & $B_{3}$ & $B_{4}$ & Weight $\left(w_{i}\right)$ \\
\hline$B_{1}$ & 1 & $2 / 3$ & 3 & 1 & 0.27 \\
\hline$B_{2}$ & $3 / 2$ & 1 & 4 & 2 & 0.41 \\
\hline$B_{3}$ & $1 / 3$ & $1 / 4$ & 1 & $1 / 2$ & 0.10 \\
\hline$B_{4}$ & 1 & $1 / 2$ & 2 & 1 & 0.22 \\
\hline
\end{tabular}

2) Construct criteria layer judgment matrix $B_{1} 、 B_{2} 、 B_{3}$ and determine the weight, as shown in Table 3-6.

Table 3. The judgment matrix and weight of sensory experience $B_{1}$

\begin{tabular}{|c|c|c|c|c|c|}
\hline$B_{1}$ & $C_{1}$ & $C_{2}$ & $C_{3}$ & $C_{4}$ & Weight $\left(w_{i}\right)$ \\
\hline$C_{1}$ & 1 & 2 & 1 & 2 & 0.33 \\
\hline$C_{2}$ & $1 / 2$ & 1 & $1 / 2$ & 1 & 0.17 \\
\hline$C_{3}$ & 1 & 2 & 1 & $1 / 2$ & 0.25 \\
\hline$C_{4}$ & $1 / 2$ & 1 & 2 & 1 & 0.25 \\
\hline
\end{tabular}

Table 4. The judgment matrix and weight of behavior experience $B_{2}$

\begin{tabular}{|c|c|c|c|c|c|}
\hline$B_{2}$ & $C_{5}$ & $C_{6}$ & $C_{7}$ & $C_{8}$ & Weight $\left(w_{i}\right)$ \\
\hline$C_{5}$ & 1 & 1 & 1 & 2 & 0.29 \\
\hline$C_{6}$ & 1 & 1 & 1 & $3 / 2$ & 0.27 \\
\hline$C_{7}$ & 1 & 1 & 1 & 2 & 0.29 \\
\hline$C_{8}$ & $1 / 2$ & $2 / 3$ & $1 / 2$ & 1 & 0.15 \\
\hline
\end{tabular}

Table 5. The judgment matrix and weight of emotional experience $B_{3}$

\begin{tabular}{|c|c|c|c|c|}
\hline$B_{3}$ & $C_{9}$ & $C_{10}$ & $C_{11}$ & Weight $\left(w_{i}\right)$ \\
\hline$C_{9}$ & 1 & 1 & 2 & 0.40 \\
\hline$C_{10}$ & 1 & 1 & 2 & 0.40 \\
\hline$C_{11}$ & $1 / 2$ & $1 / 2$ & 1 & 0.20 \\
\hline
\end{tabular}

Table 6. The judgment matrix and weight of economy $B_{4}$

\begin{tabular}{|c|c|c|c|c|}
\hline$B_{4}$ & $C_{12}$ & $C_{13}$ & $C_{14}$ & Weight $\left(w_{i}\right)$ \\
\hline$C_{12}$ & 1 & 5 & 1 & 0.48 \\
\hline$C_{13}$ & 1 & 1 & $1 / 3$ & 0.11 \\
\hline$C_{14}$ & $1 / 2$ & 2 & 1 & 0.41 \\
\hline
\end{tabular}

4.3 Consistency test

After determining the judgment matrix and weight of every element, the consistency test is performed as follows:

$$
C I=\left(\lambda_{\max }-n\right) /(n-1)
$$


Where $\lambda_{\max }$ is the maximum eigenvalue, $\lambda_{\max }=\sum_{1}^{n} \frac{(B W)_{i}}{n W_{i}},(B W)_{i}$ represent the ith component of vector BW, and $\mathrm{n}$ is the order of the matrix.

The average random consistency index RI is available in Table 7 , Where CR $=\mathrm{CI} / \mathrm{RI}$. If $\mathrm{CR} \leq 0.1$, the consistency test is valid, otherwise it needs to be recalculated.

Table 7. Average random consistency index

\begin{tabular}{|c|c|c|c|c|c|c|c|c|c|}
\hline Matrix dimension $(\boldsymbol{n})$ & $\mathbf{1}$ & $\mathbf{2}$ & $\mathbf{3}$ & $\mathbf{4}$ & $\mathbf{5}$ & $\mathbf{6}$ & $\mathbf{7}$ & $\mathbf{8}$ & $\mathbf{9}$ \\
\hline $\boldsymbol{R I}$ & 0 & 0 & 0.58 & 0.90 & 1.12 & 1.24 & 1.32 & 1.41 & 1.45 \\
\hline
\end{tabular}

The results of the consistency test are shown in Table 8. Every CR value is less than 0.1, and the consistency test is valid.

Table 8. Conformity test results

\begin{tabular}{|c|c|c|c|c|c|}
\hline & $A$ & $B_{1}$ & $B_{2}$ & $B_{3}$ & $B_{4}$ \\
\hline$\lambda_{\max }$ & 4.02 & 4.25 & 4.00 & 3.00 & 3.01 \\
\hline$C I$ & 0.01 & 0.08 & 0 & 0 & 0 \\
\hline$C R$ & 0.01 & 0.09 & 0 & 0 & 0 \\
\hline
\end{tabular}

4.4 Comprehensive weight

After the consistency test is completed, the weights of all elements are integrated to form the home chairs design evaluation system based on user experience for low-and middle-income groups, as shown in Table 9.

Table 9. The comprehensive weight of each factor

\begin{tabular}{|c|c|c|c|c|c|c|c|c|c|c|c|c|c|c|}
\hline & $C_{1}$ & $C_{2}$ & $C_{3}$ & $C_{4}$ & $C_{5}$ & $C_{6}$ & $C_{7}$ & $C_{8}$ & $C_{9}$ & $C_{10}$ & $C_{11}$ & $C_{12}$ & $C_{13}$ & $C_{14}$ \\
\hline$B_{1}$ & 0.33 & 0.17 & 0.25 & 0.25 & - & - & - & - & - & - & - & - & - & - \\
\hline$B_{2}$ & - & - & - & - & 0.29 & 0.27 & 0.29 & 0.15 & - & - & - & - & - & - \\
\hline$B_{3}$ & - & - & - & - & - & - & - & - & 0.40 & 0.40 & 0.20 & - & - & - \\
\hline$B_{4}$ & - & - & - & - & - & - & - & - & - & - & - & 0.48 & 0.11 & 0.41 \\
\hline$W_{i}$ & 0.089 & 0.046 & 0.068 & 0.068 & 0.119 & 0.111 & 0.119 & 0.062 & 0.040 & 0.040 & 0.020 & 0.106 & 0.024 & 0.090 \\
\hline
\end{tabular}

\section{Discussion}

\subsection{Scheme analysis}

According to the results of the comprehensive weights of all elements above, 3 home chair design schemes for low-and middle-income groups are evaluated comprehensively. First, 3 home chairs on the market are selected as evaluation scheme X, Y and Z. As shown in Table 10, 15 decision makers will score 0 to 10 points for every element of the neutron criterion layer in evaluation system. Table 11 shows the makers' scores (means) for the 3 schemes.

Table 10. 3 schemes and their basic information

\begin{tabular}{|c|c|c|c|}
\hline Scheme & Picture & Material & Reference price \\
\hline $\boldsymbol{X}$ & & & \\
& & & \\
& & & \\
\hline
\end{tabular}




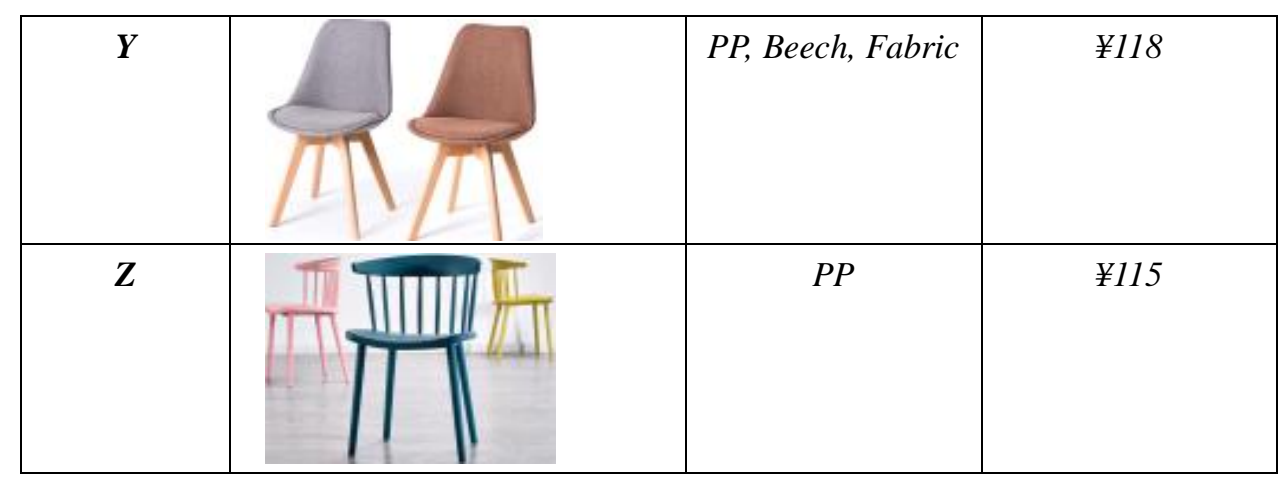

Table 11. Maker score (mean) results of the 3 schemes

\begin{tabular}{|c|c|c|c|c|c|c|c|c|c|c|c|c|c|c|}
\hline & $C_{1}$ & $C_{2}$ & $C_{3}$ & $C_{4}$ & $C_{5}$ & $C_{6}$ & $C_{7}$ & $C_{8}$ & $C_{9}$ & $C_{10}$ & $C_{11}$ & $C_{12}$ & $C_{13}$ & $C_{14}$ \\
\hline$X$ & 6.93 & 8.00 & 8.29 & 8.07 & 8.14 & 7.71 & 7.00 & 9.71 & 7.07 & 6.85 & 7.64 & 5.14 & 8.43 & 7.86 \\
\hline$Y$ & 8.42 & 8.07 & 8.21 & 8.00 & 8.07 & 8.42 & 8.29 & 7.43 & 8.43 & 8.71 & 8.21 & 7.92 & 8.07 & 8.07 \\
\hline$Z$ & 7.93 & 7.78 & 8.14 & 4.93 & 7.17 & 7.35 & 6.93 & 7.14 & 8.43 & 8.07 & 7.07 & 7.92 & 6.29 & 6.07 \\
\hline
\end{tabular}

The evaluation score of scheme $\mathrm{X}$ can be calculated from table 9 as

$$
\mathrm{N}_{\mathrm{X}}=6.93 \times 0.089+8.00 \times 0.046+\cdots+7.86 \times 0.090=7.52
$$

By analogy, the evaluation score of scheme $\mathrm{Y}$ is 8.18 , and scheme $\mathrm{Z}$ is 7.23 . It can be seen that the comprehensive ranking of $\mathrm{X}, \mathrm{Y}$ and $\mathrm{Z}$ home chair schemes is: $\mathrm{Y}>\mathrm{X}>\mathrm{Z}$, scheme $\mathrm{Y}$ is the best.

\subsection{Verification of evaluation results}

After ranking, the ranking results of the evaluation method need to be tested. The test method mainly relies on the month sales and comments of the 3 schemes on Taobao. Due to the large fluctuation of Taobao price, only one shop's sales and comments are not enough to ensure the accuracy of the data, the upper and lower $10 \%$ of the reference price in Table 10 is the reasonable price ${ }^{[13]}$. That is, the reasonable price of scheme $\mathrm{X}$ is 169 207 yuan, scheme $\mathrm{Y}$ is 106 130 yuan, scheme $\mathrm{Z}$ is 104 127 yuan. In the reasonable price range, the top three shops of every scheme are selected to obtain data. The final data is summarized in Table 12. It is observed that the monthly sales and comments of scheme $Y$ are far more than others, and the ranking is $\mathrm{Y}>\mathrm{X}>\mathrm{Z}$. The verification shows that the ranking in Table 12 are consistent with the results obtained by the evaluation method, so the evaluation method is effective.

Table 12. Data collection of 3 schemes in Taobao

\begin{tabular}{|c|c|c|c|c|c|c|}
\hline Scheme & \multicolumn{3}{|c|}{ Month sales } & \multicolumn{3}{|c|}{ Number of comments } \\
\hline $\mathrm{X}$ & 2066 & 1804 & 1700 & 3483 & 3450 & 4012 \\
\hline $\mathbf{Y}$ & 4943 & 3346 & 2777 & 15180 & 8542 & 8352 \\
\hline $\mathrm{Z}$ & 1092 & 1030 & 606 & 2386 & 1808 & 995 \\
\hline
\end{tabular}

\section{Conclusion}

Attention in low-and middle-income groups' home living environment, based on the theory of user experience, a multi-layer and multi-element design evaluation model for sensory, behavioral, emotional, and economical experiences is established. Users participate in the design process of home chairs, determine the weight of every element in the valuation system, and form the evaluation method of home chairs design for low-and middle-income groups.

1) The weight of every element in the evaluation criteria layer is sensory experience $\left(B_{1}\right), 27 \%$; behavioral experience $\left(\mathrm{B}_{2}\right), 41 \%$; emotional experience $\left(\mathrm{B}_{3}\right), 10 \%$; economic experience $\left(\mathrm{B}_{4}\right), 22 \%$. 
2)The weight of every element in the sub-criterion layer is shape $\left(C_{1}\right), 0.089$; color $\left(C_{2}\right)$, 0.046; decoration $\left(C_{3}\right)$, 0.068; material $\left(C_{4}\right), 0.068$; function $\left(C_{5}\right), 0.119$; structure $\left(C_{6}\right), 0.111$; ergonomics $\left(C_{7}\right), 0.119$; mobile storage $\left(\mathrm{C}_{8}\right)$, 0.062; personalization $\left(\mathrm{C}_{9}\right), 0.040$; detail $\left(\mathrm{C}_{10}\right), 0.040$; sense of belonging $\left(\mathrm{C}_{11}\right), 0.020$; price $\left(\mathrm{C}_{12}\right), 0.106$; environmental protection $\left(\mathrm{C}_{13}\right), 0.024$ and use cycle $\left(\mathrm{C}_{14}\right), 0.090$.

3) The introduction of AHP can transform the multi-element and fuzzy design evaluation problem into a comprehensive solution of qualitative and quantitative combination, which improves the accuracy of design evaluation and provides a reference for the similar products' design evaluation.

\section{Acknowledgments}

This work was supported by the National Science and Technology Major Project of China under Grant No. 2016ZX05038-002-LH001, the National Natural Science Foundation of China under Grant No. 51275057 and 51704034, and the Post-graduate education and teaching research project of Yangtze University under Grant No. YJY2019024.

\section{References}

[1] Cheng, H., Li Y. F., (2014) "Evaluation Model of Furniture Design Scheme Based on Analytic Hierarchy Process," Packaging Engineering 35(14), 37-41.

[2] Cui, Y. L., (2012) "Research on The Form Space of Products," The Study on Art Education (18), 63.

[3] Zhu, L. N., Chen, B. F., (2011) "Behavioral Experience in Product Design," Chinese Journal of Ergonomics (2), 77-80.

[4] Ou, Y. B., He, Y., (2006) "User Research and User Experience Design," Journal of Jiangsu University (Natural Science Edition) 27(5A), 55-57.

[5] Guo, J., Zhou, M. C., Li Z., et al, (2015) “Green design assessment of electromechanical products based on group weighted-AHP,” Enterprise Information Systems 9(8), 878-899.

[6] Chang, Y., Liu, B. S., Tian, Y., (2017) "Method and Application of Fuzzy Comprehensive Evaluation of Sweeping Vehicle Modeling Based on AHP,” Mechanical Design 34(03), 121-125.

[7] Ulloa, C., Nuñez, J. M., Lin, C. X., et al, (2018) “AHP-based design method of a lightweight, portable and flexible air-based PV-T module for UAV shelter hangars," Renewable Energy 123, 767-780.

[8] Wu, Q., (2018) “The Differentiation of User Experience Design,” Art \& Design (10), 30-33.

[9] Wan, Q., You, X., Song, S. S., (2017) "New Chinese Style Furniture Design Based on User Experience," Packaging Engineer 38(14), 106-109.

[10]Chen, Z. J., Jiang, S. L., Guan, H. Y., (2010) “Evaluation Model of Furniture Design Scheme Based on Analytic Hierarchy Process” Scientia Silvae Sinicae 46(12), 130-136.

[11]Huang, H., Yang, M. G., (2016) "Research on Usability of Intelligent Products for The Elderly Based on Kansei Engineering,” Mechanical Design 33(4), 109-112.

[12] Saaty, T. L., Vargas, L. G., (2012) Models, methods, concepts \& applications of the analytic hierarchy process, Springer US, New York, Chapter 3.

[13] The Association of China Refractories Industry, (2017) Establish a scientific and reasonable price system to avoid disorderly competition in the market, China Building Materials News, 12(11), 004. 